DOI https://doi.org/10.15589/znp2020.3(481).9

УДК 004:625.748.54

\title{
ANALYSIS OF SELF SERVICE SYSTEM METHODS AT GAS STATIONS
}

\section{АНАЛІЗ МЕТОДІВ СИСТЕМИ САМООБСЛУГОВУВАННЯ НА АЗС}

\author{
Oksana V. Haidaienko \\ okotsur80@gmail.com \\ ORCID: 0000-0002-6614-5443 \\ Hanna S. Morozova \\ amorozova711004@gmail.com \\ ORCID: 0000-0003-0773-4309 \\ Nataliia V. Tenditna \\ hfnuk@gmail.com \\ ORCID:0000-0002-4553-7907 \\ Mykola V. Shcherbynin \\ nikoshherbinink@gmail.com \\ ORCID: 0000-0001-7983-8209
}

\author{
О. В. Гайдаєнко, \\ доцент кафедри ІУСТ \\ г. С. Морозова, \\ ст. викладач кафедри ІУСТ \\ Н. В. Тендітна, \\ ст. викладач кафедри IT та Ф-МД \\ М. В. Щербинін \\ студент
}

Admiral Makarov National University of Shipbuilding, Mykolaiv

Національний університет кораблебудування імені адмірала Макарова, м. Миколаӥв

\begin{abstract}
During the study, the methods of service at modern gas stations were considered and given the fact that every year the number of cars in Ukraine can often be observed when there are queues and quarrels at gas stations due to long service, competition between gas stations has many factors but one of the main is quality fuel and service time, whether there are workers who will refuel your car, whether there are self-service terminals or speakers with a built-in self-service terminal, what is the attitude of gas station employees to their customers.

Analysis of the gas station market in Ukraine is an important and relevant topic. During the research of the topic, it was found that the method of queuing, namely the queuing system in the flow, is the most suitable for the work of service at the gas station. The study also considered the main problems of service, the history of technical progress in the field of service at the gas station, determined the future effectiveness of the proposed technology compared to existing ones. The main parameters of gas station operation, which positively affect customer satisfaction are quality fuel, convenience of location, courtesy and friendliness of operators, speed of service, cleanliness at gas stations and opportunity. Of all the parameters, two main ones can be distinguished, namely service time and fuel quality. Service time depends on the method of service. There are three ways of service, namely personnel service, terminal service, service by means of a column with the self-service terminal, each of these methods has the advantages and disadvantages.

While in Europe, self-service terminals are being replaced by speakers with a built-in terminal and software is being upgraded, in Ukraine, unfortunately, you can see that only gas station units have self-service terminals, and gas stations with a built-in terminal are generally from the fiction section for more fun customer service should be automated and the introduction of self-service columns in gas stations in Ukraine is essential, so I decided to prove that customer service equipment directly affects customer loyalty and satisfaction and increases service speed, increases the economic efficiency of gas stations and research results this is definitely proven.
\end{abstract}

Key words: queuing method; Gas station; technical progress, efficiency of the offered technology in comparison with existing.

Анотація. Під час дослідження були розглянуті методи обслуговування на сучасних АЗС. Враховуючи те, що 3 кожним роком збільшується кількість авто в Україні, часто можна спостерігати ситуацію, коли на АЗС виникають черги і сварки через довге обслуговування. Конкуренція між АЗС має безліч факторів, але одними із основних $є$ якість пального та час обслуговування, чи $є$ робітники, які заправлять вам авто, чи $є$ термінали самообслуговування або колонки із вбудованим терміналом самообслуговування, яке ставлення працівників АЗС до своїх клієнтів.

Аналіз ринку АЗС в Україні є важливою та актуальною темою. В ході дослідження теми було встановлено, що для роботи обслуговування на АЗС найбільше підходить метод масового обслуговування, а саме систе- 


\section{КОМП'ЮТЕРНІ НАУКИ ТА ІНФОРМАЦІЙНІ ТЕХНОЛОГІЇ №3-2020}

ми масового обслуговування в потоці. Під час дослідження також було розглянуто основні проблеми обслуговування, історію технічного прогресу у сфері обслуговування на АЗС, визначено майбутню ефективність запропонованої технології порівняно з існуючими.

Основними параметрами роботи АЗС, які позитивно впливають на задоволеність клієнтів, є якісне паливо, зручність розташування, ввічливість і доброзичливість операторів, швидкість обслуговування, чистота на АЗС. 3 усіх параметрів можна виділити два основних, а саме час обслуговування і якість пального. Час обслуговування залежить від способу обслуговування. $Є$ три способи обслуговування, а саме обслуговування персоналом, обслуговування терміналом, обслуговування за допомогою колонки з терміналом самообслуговування, у кожного з яких є свої переваги і недоліки.

У Свропі термінали самообслуговування змінюють на колонки із вбудованим терміналом і модернізують ПЗ в них. В Україні, на жаль, можна побачити, що лише на одиницях АЗС стоять термінали самообслуговування, а автозаправні колонки із вбудованим терміналом - це взагалі з розділу фантастики. Для більшого задоволення клієнтів послуги мають автоматизуватися, тому введення у роботу на АЗС мережах в Україні колонок самообслуговування украй необхідне. Ми прагнемо довести, що обладнання, яке обслуговує клієнтів напряму, впливає на рівень лояльності та задоволеності клієнтів і підвищує швидкість обслуговування, збільшує економічну ефективність АЗС, що довели результати дослідження.

Ключові слова: метод масового обслуговування; АЗС; технічний прогрес, ефективність запропонованої технології порівняно з існуючими.

\section{ПОСТАНОВКА ЗАДАЧІ}

3 появою перших автомобільних заправних станцій (далі - АЗС) на початку XX століття питання обслуговування почали виносити на перші позиції, адже мережам АЗС потрібно було створювати конкуренцію одне одному і залучати нових клієнтів. Спочатку з'явилися люди, які заправляли автомобіль, пізніше додаткові послуги - миття вікон чи протирання ковпаків на колесах. Приблизно тоді ж фахівці, які займалися цими питаннями, почали звертатися до методу масового обслуговування з метою покращення обслуговування та збільшення прибутків на АЗС шляхом виявлення факторів, які впливають на їх ефективність. Враховуючи швидкий технологічний ріст на той час у всьому світі, сфера АЗС не стала виключенням. До факторів, які впливали на обслуговування, потрапило і обладнання, встановлене на АЗС.

На сучасній АЗС можна побачити такі додаткові послуги як магазин, кафе чи туалет. Проблеми з цими сервісами впливають на рівень обслуговування і лояльності клієнта, але основною проблемою все ж $є$ низька швидкість обслуговування через застарілі технології, що впливає на виникнення черг і незадоволеність клієнтів, введення нових технологій вирішує ці проблеми.

\section{АНАЛІЗ ОСТАННІХ ДОСЛІДЖЕНЬ І ПУБЛІКАЦІЙ}

При вивченні та аналізі праць і публікацій, які містять дослідження у сфері обслуговування на АЗС та ефективність різних методів, у тому числі і методу масового обслуговування, було звернуто увагу на роботу Т.В. Сушкової [1], у якій досліджувалися пріоритети споживчих переваг на ринку АЗС і було розкрито тему впливу їх на обслуговування та задоволення споживачів послуг. У [2] проведено дослідження рівня лояльності і задоволеності споживачів послуг на АЗС і вплив обслуговування на ці рівні.
У роботах розкривається тема масового обслуговування на АЗС, чинники, які впливають на рівень задоволеності клієнтів, але жодна 3 них не включає до цих чинників застаріле обладнання та технології, що впливають на швидкість обслуговування та задоволеність клієнтів і розраховують економічну ефективність, відштовхуючись лише від побічних проблем в обслуговуванні.

\section{МЕТА ДОСЛІДЖЕННЯ}

Мета дослідження полягає у підвищенні ефективності роботи АЗС шляхом впровадження розробленого на основі запропонованого методу масового обслуговування ПЗ для колонок самообслуговування із вбудованим терміналом.

\section{ОСНОВНИЙ МАТЕРІАЛ}

Питання якості обслуговування на автозаправних станціях вже давно $є$ однією $з$ основ конкурентної боротьби. Варто зазначити, що питання якості сервісу на АЗС є актуальними не тільки для автомобілістів основних споживачів послуг, а й для державних регулюючих органів, які останніми роками намагаються навести порядок у галузі.

Ще кілька десятиліть тому (в 90-х роках минулого століття) заправки в Україні дуже відрізнялися від існуючих: здебільшого це були так звані контейнерні автозаправні станції, які представляли собою найпростіший набір найнеобхіднішого обладнання. Часто вони будувалися навіть без проектно-кошторисної документації, проведення державної технічної та екологічної експертизи, не кажучи вже про висунення до них вимог по архітектурі, дизайну і якості обслуговування. Але в міру становлення галузі їх формат дуже змінився.

Сучасна автозаправна станція давно перестала бути місцем, де продається тільки бензин. Нині це місце, де можна отримати додаткові товари і послуги: придбати автоаксесуари і продукти, перекусити 
і випити кави, підкачати колеса, помити скло автомобіля, скористатися туалетом. Надання подібних послуг - основа розвитку АЗС і залучення клієнтів. Яка якість цих послуг нині, які слабкі сторони обслуговування і який потенціал для розвитку галузі, розбиралася компанія Profpoint [2], яка з 2006 року займається моніторингом якості обслуговування АЗС.

За даними, які вдалося отримати в процесі досліджень, основними параметрами роботи АЗС, які позитивно впливають на задоволеність клієнтів, є якісне паливо, зручність розташування, ввічливість і доброзичливість операторів, швидкість обслуговування, чистота на АЗС і наявність кави. У свою чергу такі фактори як незручний заїзд, відсутність магазину і незацікавленість оператора, незадовільний стан або відсутність туалетів є основними причинами невдоволення клієнтів. Усунення цих «стоп-факторів» сприяє підвищенню рівня лояльності клієнтів АЗС.

Також одним із головних факторів $є$ час обслуговування та черги, особливо актуальні ці два фактори на $\mathrm{A} 3 \mathrm{C}$, розташованих на трасах, де часто виникають затори через малу кількість АЗС на 100 км. Якщо брати до уваги АЗС, то тут найбільше підходять системи з очікуванням при необмеженому вході потоку. Схема алгоритму системи масового обслуговування в потоці наведена на рисунку 1 [3].

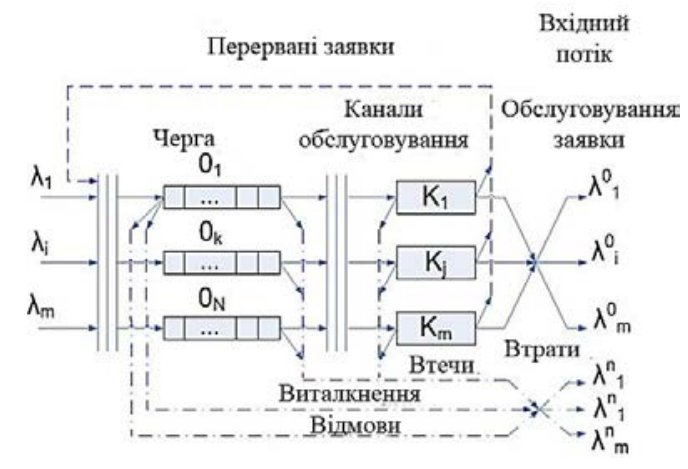

Рис. 1. Схема алгоритму системи масового обслуговування в потоці

На n однакових каналів надходить найпростіший потік заявок інтенсивністю $\lambda$. Якщо в момент надходження заявки всі канали зайняті, то ця заявка стає в чергу і чекає початку обслуговування. Час обслуговування кожної заявки є випадковою величиною, яка підпорядковується експоненціальним законом розподілу з параметром $\mu$.

Ймовірність того, що всі канали вільні обраховується за формулою:

$$
P_{0}=\left[\sum_{k=0}^{n-1} \frac{p^{k}}{k !}+\frac{p^{n}}{(n-1) !(n-p)}\right]^{-1}
$$

Ймовірність того, що зайнято $\mathrm{k}$ каналів, за умови, що загальна кількість заявок, які знаходяться на обслуговуванні, не перевищує кількості каналів:

$$
P_{k}=\frac{p^{k}}{k !} * p_{0}, 1 \leq k \leq n
$$

Ймовірність того, що в системі знаходиться k заявок, у разі, коли їх кількість більша кількості каналів:

$$
P_{k}=\frac{p^{k}}{n ! n^{k-n}} * p_{0}, k>n
$$

Вірогідність того, що всі канали займаються:

$$
\pi=\frac{p^{n}}{(n-1) !(n-p)} * p_{0}, \frac{p}{n}<1
$$

Середній час очікування заявляв начальну підтримку у системах:

$$
t_{\text {ож }}=\frac{\pi}{\mu^{*}(n-p)}
$$

Середня довжина черги:

$$
L_{\text {оч }}=\frac{p^{*} \pi}{n-p}
$$

Середня кількість вільних від обслуговування каналів:

$$
N_{0}=\sum_{k=0}^{n-1}(n-k) * P_{k}
$$

Автозаправна станція 3 двома колонками обслуговує пуассоновий потік машин 3 інтенсивністю $\lambda=0,8$ машин за хвилину. Час обслуговування однієї машини підпорядковується показовому закону із середнім значенням 2 хвилини. У цьому районі немає іншої АЗС, тому черга перед АЗС може зростати практично необмежено. Будемо вираховувати:

1) середню кількість зайнятих колонок;

2) ймовірність відсутності черги в АЗС;

3) ймовірність того, що доведеться чекати початку обслуговування;

4) середню кількість машин у черзі;

5) середній час очікування у черзі;

6) середній час перебування машини на АЗС;

7) середня кількість машин на АЗС.

За умовою завдання $\mathrm{n}=2, \lambda=0.8 ; \mu=1 / \mathrm{t}_{\text {обсл }}=0.5$; $\rho=\lambda / \mu=1.6$. Оскільки $\rho / n=0,8<1$, то черга не зростатиме безмежно і $є$ сенс говорити про граничний стаціонарний режим роботи системи масового обслуговування.

Знаходимо ймовірності станів СМО:

$$
\begin{gathered}
P_{0}=\left[\sum_{k=0}^{1} \frac{1,6^{k}}{k !}+\frac{1,6^{2}}{(2-1) !(2-1,6)}\right]^{-1}=\left[1+1,6+\frac{1,6^{2}}{1 !^{*} 0,4}\right]^{-1}=\frac{1}{9} \approx 0,11111 \\
P_{1}=\frac{1,6^{1}}{1 !} * p_{0}=1,6 p_{0} \approx 0,1778 ; p_{2}=\frac{1,6^{2}}{2 !} * p_{0}=1,28 p_{0} \approx 0,1422 \\
p_{3}=\frac{1,6^{3}}{2 ! 2^{9-2}} * p_{0}=1,024 p_{0} \approx 0,1138
\end{gathered}
$$

Середня кількість зайнятих колонок:

$\mathrm{N}_{\text {зан }}=\mathrm{n}-\mathrm{N}_{0}=2\left(2 \mathrm{p}_{0}+1 \mathrm{p}_{1}\right)=2-20.1111-0.1778=1.6$ $\mathrm{N}_{\text {зан }}^{\text {зан }}=\mathrm{n}-\mathrm{N}_{0}=2\left(2 \mathrm{p}_{0}+1 \mathrm{p}_{1}\right)=2-20.1111-0.1778=1.6$

Ймовірність відсутності черги на АЗС:

$$
\mathrm{p}_{0}+\mathrm{p}_{1}+\mathrm{p}_{2}=0.1111+0.1778+0.1422=0.4311
$$




\section{КОМП'ЮТЕРНІ НАУКИ ТА ІНФОРМАЦІЙНІ ТЕХНОЛОГІЇ № Зロ 2020}

Ймовірність того, що доведеться чекати початку обслуговування, дорівнює ймовірності того, що всі колонки зайняті:

$$
\mathrm{p}_{0}+\mathrm{p}_{1}+\mathrm{p}_{2}=0.1111+0.1778+0.1422=0.4311
$$

Середня кількість машин у черзі:

$$
L_{\text {ou }}=\frac{p^{*} \pi}{n-p}=\frac{1,6 * 0,7111}{2-1,6} \approx 2,8444
$$

Середній час очікування у черзі:

$$
t_{\text {ож }}=\frac{\pi}{\mu^{*}(n-p)}=\frac{0,7111}{0,5 *(2-1,6)} \approx 3,5556 \text { мін }
$$

Середній час перебування машини на АЗС:

$$
\mathrm{t}_{\text {преб }}=\mathrm{t}_{\text {обсл }}+\mathrm{t}_{\text {ож }}=2+3.5556=5.5556 \text { хв. }
$$

Середня кількість машин на АЗС:

$$
\mathrm{N}_{\text {зан }}+\mathrm{L}_{\text {оч }}=1.6+2.8444=4.4444 \text { [4] }
$$

Якщо брати за основу обслуговування при продажі палива, можна виділити три способи: обслуговування персоналом, обслуговування терміналом та обслуговування за допомогою введення IC у колонку із терміналом самообслуговування. Порівняння способів обслуговування на АЗС наведено у таблиці 1.

Для наглядного порівняння методів обслуговування була змодельована модель кожного із методів обслуговування у середовищі Anylogic [5]. Було враховано більшість факторів, які можуть вплинути на час обслуговування, наприклад кількість пального, що заправляється, відстань, яку необхідно подолати від колонки до каси, час, який необхідно витратити оператору на обслуговування клієнта. Для більш точного тесту було встановлено випадкову кількість автомобілів у потоці, час моделювання - 1 година. Результати моделювання наведені на рисунках 2-4. Структура моделі АЗС в Anylogic представлена на рисунку 5.

\section{ОБГОВОРЕННЯ ОТРИМАНИХ РЕЗУЛЬТАТІВ}

Як можна побачити з результатів, кількість обслугованих автомобілів за годину 3 використанням запропонованого нами методу в 4 рази більша. Це означає, що за годину при середній вартості пального 22 гривні за літр АЗС отримала б 1794 гривень за літр, в той час як зі звичайним живим обслуговуванням - лише 414 гривень, терміналом самообслуговування - 1403 гривні. Враховуючи це, було проведено дослідження і опитано 165 водіїв. У результаті цього дослідження було виявлено, що найчастіше водії заправляють 10 літрів пального, а це 17940 гривень за годину при 22 гривнях за літр пального 95. Було зіставлено топ найпопулярніших видів пального, якщо не враховувати ГАЗ, відштовхуючись від власних досліджень:

Пальне 95 - 65 осіб.

Пальне 92 - 55 осіб.

Пальне 95 євро - 32 особи.

Інші види палива (98, ГАЗ) - 13 осіб.

На питання, чи хотіли б водії побачити поді-

\begin{tabular}{|c|c|c|}
\hline Метод & Переваги & Недоліки \\
\hline $\begin{array}{c}\text { Обслуговування } \\
\text { персоналом }\end{array}$ & $\begin{array}{c}\text { Живе обслуговування, більш широкий спектр } \\
\text { додаткових послуг }\end{array}$ & $\begin{array}{c}\text { Наявність людського фактору, додаткові } \\
\text { затрати на зарплатню для персоналу, потрібне } \\
\text { обслуговування IC на комп'ютері касира, } \\
\text { необхідне додаткове касове обладнання, } \\
\text { наявність фактору недоброзичливого } \\
\text { персоналу, мала швидкість обслуговування, } \\
\text { виникнення черги } \\
\end{array}$ \\
\hline $\begin{array}{c}\text { Обслуговування } \\
\text { терміналом }\end{array}$ & $\begin{array}{c}\text { Може встановлюватися в додаток до живого } \\
\text { обслуговування, має можливість оплати як } \\
\text { карткою, так і готівкою, видає чеки, має більшу } \\
\text { швидкість обслуговування порівняно з живим } \\
\text { обслуговуванням, встановлюється поблизу } \\
\text { колонки, що зменшує час на обслуговування, } \\
\text { має зручний інтерфейс } \\
\end{array}$ & $\begin{array}{c}€ \text { фактор збою, має застаріле ПЗ, дуже дорогий } \\
\text { для установки, здебільшого встановлюється } \\
1-2 \text { шт. на АЗС, виникнення черги, необхідність } \\
\text { обслуговування, довгі строки обробки запитів } \\
\text { на виконання транзакцій }\end{array}$ \\
\hline $\begin{array}{c}\text { Обслуговування за } \\
\text { допомогою колонки } \\
\text { із терміналом } \\
\text { самообслуговування }\end{array}$ & $\begin{array}{c}\text { Вбудовується як окремий монітор у будь- } \\
\text { яку колонку, має зручний і зрозумілий } \\
\text { інтерфейс, дешевий для установки, зменшує } \\
\text { затрати компанії на персонал, не створює } \\
\text { черги, забезпечує вдвічі більшу швидкість } \\
\text { обслуговування, є можливість оплати } \\
\text { через інтернет, видає чеки, має можливість } \\
\text { віддаленого доступу для усунення проблем, } \\
\text { дешевший в обслуговуванні, сучасна IC та АЗ }\end{array}$ & Є фактор збою, необхідність обслуговування \\
\hline
\end{tabular}
бні колонки на наших АЗС, 158 опитаних відповіли «ТАК», 7 осіб відповіли, що їм «БАЙДУЖЕ», але ні одна людина не відповіла «НІ».

Таблиця 1. Недоліки та переваги методів обслуговування на АЗС 


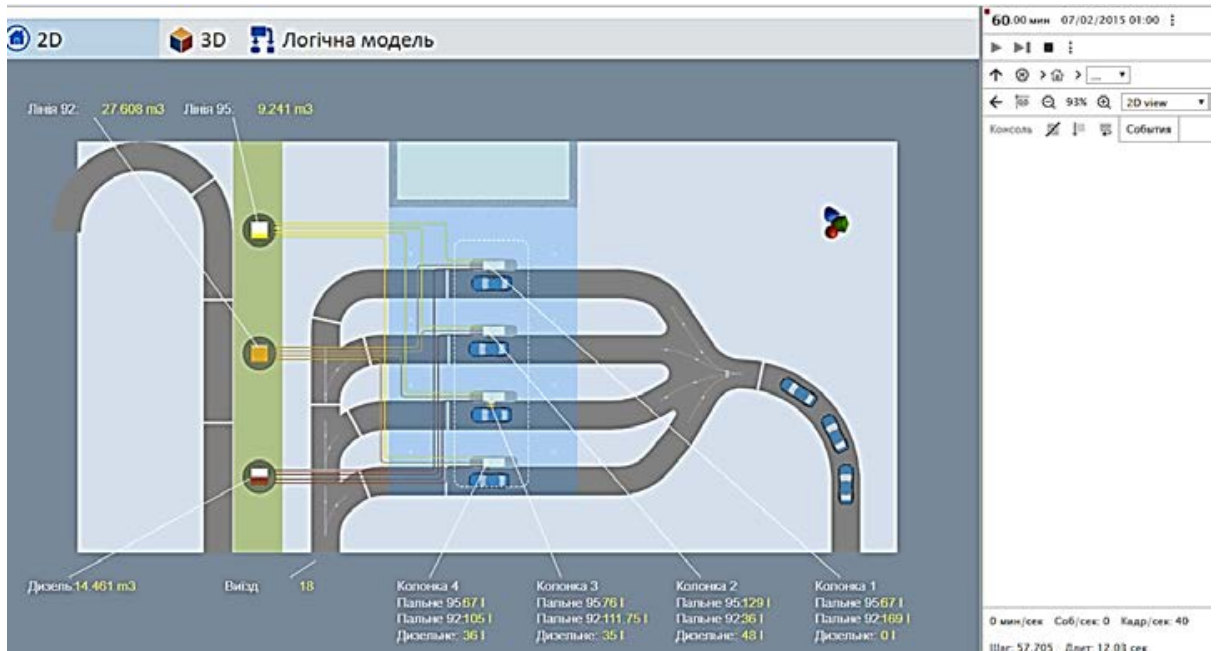

Рис. 2. Результат моделі зі звичайним живим обслуговуванням

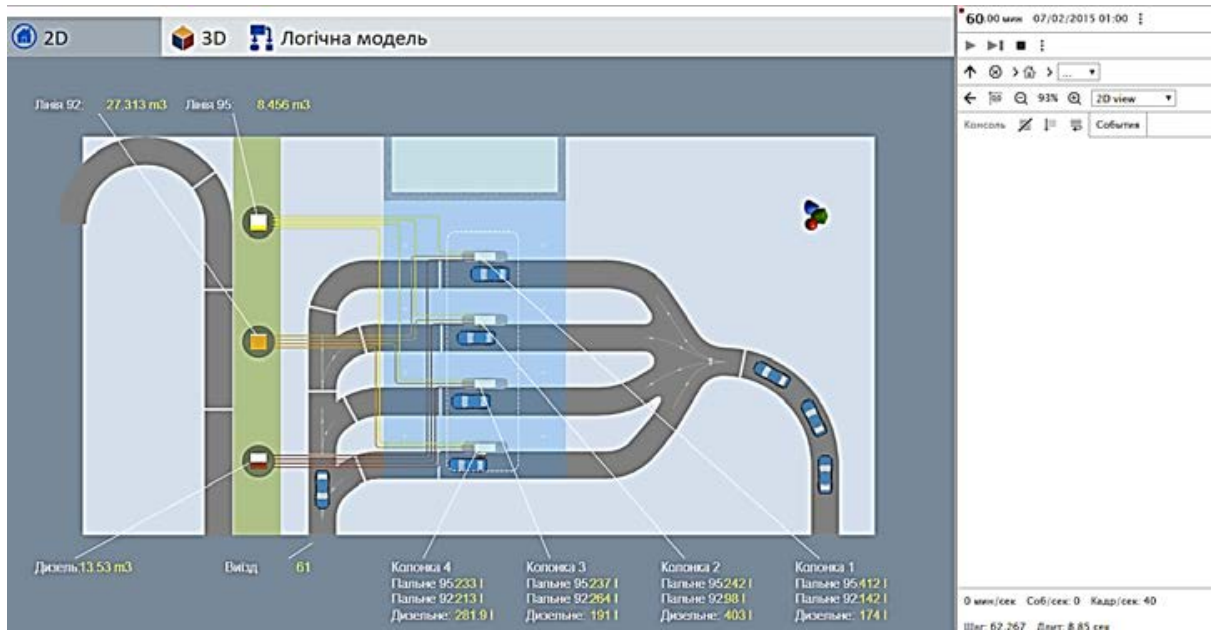

Рис. 3. Результат моделі з використанням терміналу самообслуговування кількістю 2 штуки

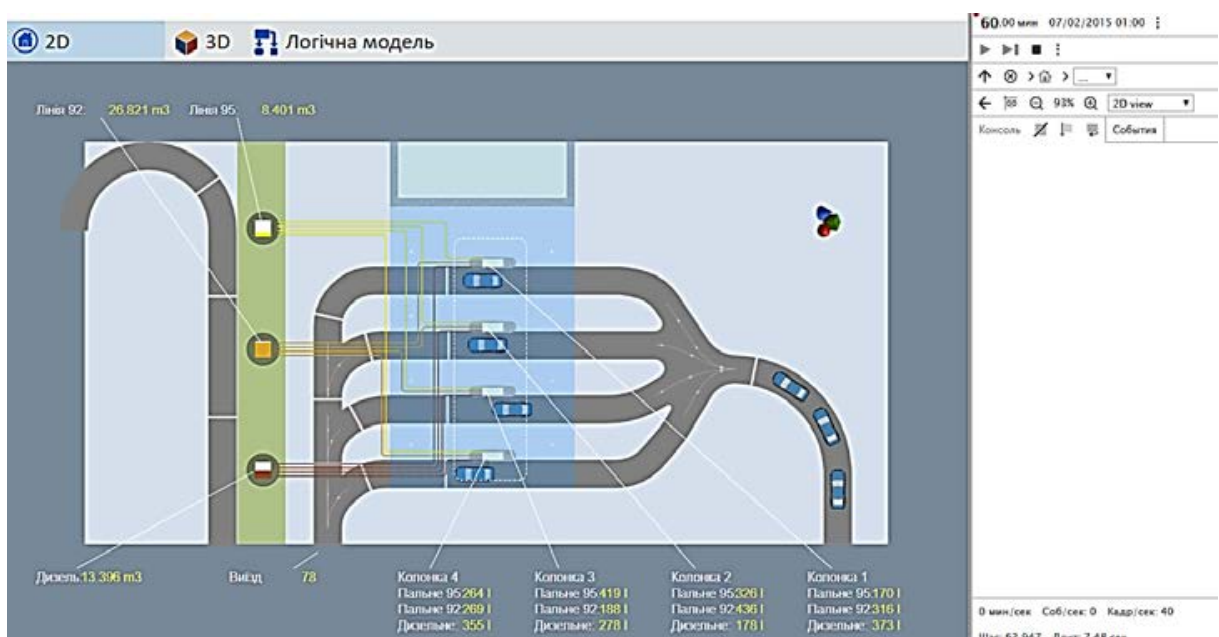

Рис. 4. Результат моделі з використанням терміналу самообслуговування з IC, вбудованого у колонку 


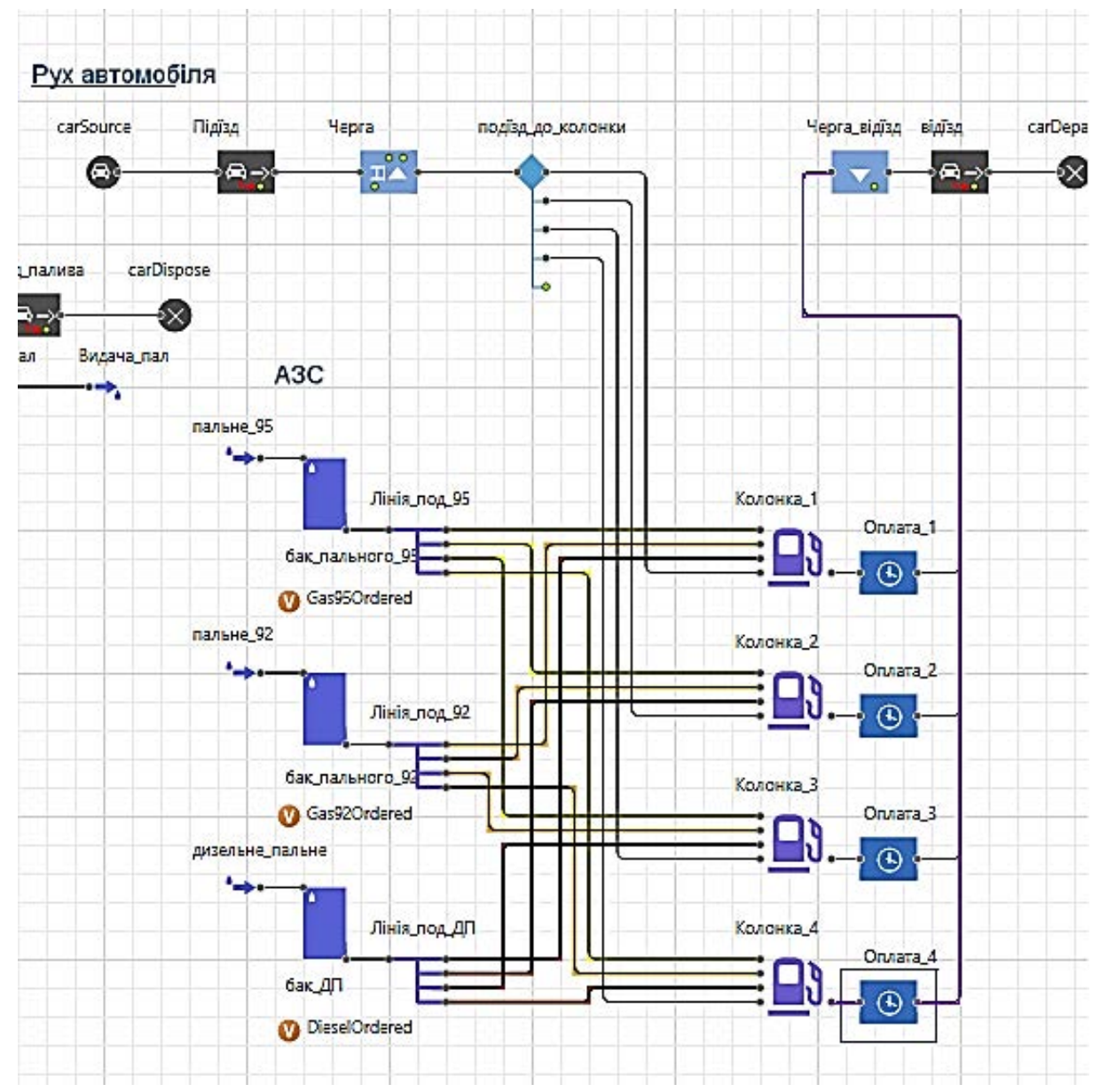

Рис. 5. Структура моделі АЗС в Anylogic

\section{ВИСНОВКИ}

У рамках дослідження проведено аналіз методів масового обслуговування на прикладі АЗС та доведено, що застаріле обладнання впливає на якість обслу- говування, рівень задоволеності клієнтів, зменшує економічну ефективність. Обраний метод обслуговування клієнтів, запропонованій у статті, є ефективнішим серед тих, що нині існують.

\section{REFERENCES}

[1] Doslidniy center kompanii Profpoin (2020). Doslidjennya NPS ta CSI kompanii Profpoin [Presented to NPS and CSI by Profpoin]. Ukraine, site page profpoint.ru "Presented". Retrieved from: http://profpoint.ru/udovletvoryonnost-potrebitelej/.

[2] Sushkova T.V. (2016). Vivchennya spozhivchikh perevag rinku AZS [Study of consumer preferences in the gas station market]. Economic presented. p. 269-272. Retrieved from: http://www.researchgate.net/publication/308748640_izucenie_ potrebitelskih_predpoctenij_na_rynke_AZS_RT.

[3] Litvinov A.L., Beketova O.M. (2018). Teoriya system masovogo obslugovuvannya [THEORY OF MASS SERVICE SYSTEMS]. Kharkiv : KHNUMG. p. 61.

[4] Sovetov B.Ya. Yakovlev S.A. (2001). Modeluvannya system : navchalniy posibnyk [Systems modeling : a textbook]. High school, p. 343.

[5] Analogichen V.V., Pobedinskiy N.S., Kuzminov M.A. (2018). Imitaciyne modeluvannya roboti AZS v seredovischi [Simulation of gas station operation in the environment]. Ukraine : Chernitsyn, p. 5-29.

\section{СПИСОК ВИКОРИСТАНОЇ ЛІТЕРАТУРИ}

[1] Дослідний центр компанії Profpoin (2020). Дослідження NPS та CSI компанії Profpoin. Україна. Сторінка сайту profpoint.ru «Дослідження». URL: http://profpoint.ru/udovletvoryonnost-potrebitelej/. 
[2] Сушкова Т.В (2016). Вивчення споживчих переваг на ринку АЗС. Економічні дослідження. С. $269-272$. URL: http://www.researchgate.net/publication/308748640_izucenie_potrebitelskih_predpoctenij_na_rynke_AZS_RT.

[3] Литвинов А.Л., Бекетова О.М. (2018). Теорія систем масового обслуговування. Харків : ХНУМГ. С. 61.

[4] Советов Б.Я., Яковлев С.А. (2001). Моделирование систем : навчальний посібник. Вища школа. С. 343.

[5] Аналогічен В.В., Побединський Н.С., Кузьмінов М.А. (2018). Імітаційне моделювання роботи АЗС в середовищі. Україна : Черніцин. С. 5-29.

(C) О. В. Гайдаєнко, Г. С. Морозова, Н. В. Тендітна, М. В. Щербинін Дата надходження статті до редакції: 16.10 .2020 Дата затвердження статті до друку: 23.10.2020 